\title{
CONTRIBUIÇÕES DA EXTENSÃO COMO INSTRUMENTO DE PROMOÇÃO DO DESENVOLVIMENTO SOCIAL, CIENTÍFICO E TECNOLÓGICO LOCAL: o papel da extensão do IFPA em Abaetetuba-PA
} Jairo da Silva e Silva ${ }^{1}$

Valdinei Mendes da Silva²

Diselma Marinho Brito ${ }^{3}$

\section{RESUMO}

O presente artigo tem como objetivo colaborar com a reflexão acerca do importante papel a ser desempenhado pela Extensão, entendida como indispensável instrumento de promoção do desenvolvimento social, científico e tecnológico nacional, regional, sobretudo, local. Desta forma, priorizamos as contribuições da Extensão do Instituto Federal do Pará - IFPA, Campus Abaetetuba, para o desenvolvimento da educação, ciência e tecnologia na Região do Baixo Tocantins Paraense, onde apresentaremos nossas experiências através dos projetos, programas e ações, salientando as conquistas e os desafios de natureza extensionista.

Palavras-chave: Extensão. IFPA Campus Abaetetuba. Desenvolvimento.

1 Professor e Coordenador Geral de Extensão do Instituto Federal de Educação, Ciência e Tecnologia do Pará - IFPA. Mestrando em Letras pela Universidade Federal do Pará. É membro do Grupo de Pesquisa GEMT Grupo de Estudos de Memórias e Culturas do Baixo Tocantins. E-mail: jairo.silva@ifpa.edu.br.

2 Diretor Geral do Instituto Federal de Educação, Ciência e Tecnologia do Pará - IFPA. Doutor em Geociências pela Universidade Federal do Pará. E-mail: valdinei.silva@ifpa.edu.br.

3 Pedagoga e Diretora Geral da Direção de Ensino, Pesquisa, Extensão, Pós-Graduação e Inovação do Instituto Federal de Educação, Ciência e Tecnologia do Pará - IFPA. Doutora em Educação Brasileira pela Universidade Federal do Ceará. E-mail: diselma.brito@ifpa.edu.br. 
CONTRIBUTIONS OF EXTENSION AS AN INSTRUMENT FOR PROMOTING LOCAL SOCIAL, SCIENTIFIC AND TECHNOLOGICAL DEVELOPMENT SPOT: the role of extension of IFPA in Abaetetuba - PA

\section{ABSTRACT}

This article aims to contribute to the reflection on the important role to be played by extension, understood as an indispensable instrument for promoting social, scientific and technological national, regional development, above all, location. Thus, we prioritize the contributions of Pará Federal Institute Extension - IFPA, Campus Abaetetuba, for the development of education, science and technology in the region of Baixo Tocantins Pará, where we will present our experiences through projects, programs and actions, highlighting achievements and the challenges of extension nature.

Keywords: Extension. IFPA Campus Abaetetuba. Development.

\section{CONTRIBUICIONES DE LA EXTENSIÓN COMO INSTRUMENTO DE PROMOCIÓN DEL DESARROLLO SOCIAL, CIENTÍFICO Y TECNOLÓGICO \\ LOCAL: el papel de la extensión del IFPA en Abaetetuba - PA}

\section{RESUMEN}

El presente artículo tiene como objetivo colaborar con la reflexión sobre el importante papel a ser desempeñado por la Extensión, entendida como una herramienta indispensable para promover el desarrollo social, científico y tecnológico nacional, regional, especialmente, local. De esta forma, priorizamos las contribuciones de la Extensión del Instituto Federal de Pará - IFPA, Campus Abaetetuba, para el desarrollo de la educación, ciencia y tecnología en la región del Bajo Tocantins Paraense, donde presentaremos nuestras experiencias a través de proyectos, programas y acciones, poniendo de relieve los éxitos y los desafíos de naturaleza extensionista.

Palabras clave: Extensión. IFPA Campus Abaetetuba. Desarrollo. 


\section{Introdução}

No âmbito da Rede Federal de Educação Profi ssional, Científi ca e Tecnológica - EPCT, a extensão, junto ao ensino e pesquisa (e inovação), ocupa posição de ampla relevância. Através da extensão, os Institutos Federais de Educação, Ciência e Tecnologia viabilizam a difusão, socialização e a democratização dos saberes já existentes e ali produzidos.

A natureza da extensão exige uma relação dialógica ${ }^{4}$ entre saberes acadêmicos e tecnológicos e saberes comunitários, promovendo, assim, a dinâmica da troca de conhecimentos. Nesse sentido, é papel protagonista da extensão, colaborar com o desenvolvimento dos diversos setores da sociedade, levando em consideração os aspectos regionais, sobretudo, locais, atendendo as demandas de suas populações, não apenas nas necessidades econômicas, mas, também, sociais, culturais e ambientais.

Assim, o presente artigo objetiva colaborar com a refl exão sobre o relevante papel a ser desenvolvido pela Extensão, compreendida como indispensável instrumento de promoção do desenvolvimento social, científi co e tecnológico nacional, regional, sobretudo, local. No entanto, este trabalho prioriza as contribuições da Extensão do Instituto Federal do Pará (IFPA) Campus Abaetetuba, para o desenvolvimento da educação, ciência e tecnologia na Região do Baixo Tocantins Paraense. Na oportunidade, descreve as experiências vivenciadas através dos projetos, programas e ações, salientando as conquistas e os desafi os de natureza extensionista.

4 Entendemos essa relação dialógica conforme a concepção bakhtiniana: "o diálogo, no sentido estrito do termo, não constitui, é claro, senão uma das formas, é verdade que das mais importantes, da interação verbal. Mas pode-se compreender a palavra 'diálogo num sentido mais amplo, isto é, não apenas como a comunicação em voz alta, de pessoas colocadas face a face, mas toda comunicação verbal, de qualquer tipo que seja. (BAKHTIN, 1995, p. 125). 


\title{
O lugar da extensão no Instituto Federal de Educação, Ciência e Tecnologia do Pará (IFPA): da teoria a prática
}

O exercício da extensão é uma as finalidades garantidas pela Lei que cria os Institutos Federais de Educação, Ciência e Tecnologia (IFs), Lei 11.892, de 29 de dezembro de 2008, a qual evidencia a responsabilidade da prática extensionista:

\begin{abstract}
VII - desenvolver programas de extensão e de divulgação científica e tecnológica;

VIII - realizar e estimular a pesquisa aplicada, a produção cultural, o empreendedorismo, o cooperativismo e o desenvolvimento científico e tecnológico;

IX - promover a produção, o desenvolvimento e a transferência de tecnologias sociais, notadamente as voltadas à preservação do meio ambiente. (BRASIL, 2008a).
\end{abstract}

Outro dispositivo legal que descreve o papel da extensão éo Extensão Tecnológica - Rede Federal de Educação Profissional, Científica e Tecnológica ${ }^{5}$, esse documento estabelece a fundamentação teórica da extensão como prática da Rede Federal de Educação Profissional, Científica e Tecnológica - EPCT, conceituando a extensão como:

Processo educativo, cultural, social, científico e tecnológico que promove a interação entre as instituições, os segmentos sociais e o mundo do trabalho com ênfase na produção, desenvolvimento e difusão de conhecimentos científicos e tecnológicos visando ao desenvolvimento socioeconômico sustentável local e regional. (FÓRUM..., 2012).

Assim, entendemos a extensão como o meio de promoção da articulação entre o saber e o fazer, considerando a realidade de cada região, articulando a vida acadêmica e os saberes locais.

5 Documento publicado em 2012, pelo Fórum de Pró-Reitores de Extensão da Rede Federal de EPCT - FORPROEXT. 
O instrumento que norteia as ações da gestão do Instituto Federal de Educação, Ciência e Tecnologia do Pará é o Plano de Desenvolvimento Institucional (PDI), o mais recente compreende o período de 2014-2018, e tem como objetivo atender às demandas necessárias para o desenvolvimento dessa instituição, dentre as quais, as externas (IFPA, 2014).

Esse mesmo documento, além de ratificar, apresenta a importância da extensão como instrumento de promoção do desenvolvimento social, científico e tecnológico local: Extensão é a interface entre o Instituto Federal e a comunidade. Constitui-se como processo educativo, cultural, científico e político que, articulado de forma indissociável com o ensino e a pesquisa, viabiliza e media a relação dialógica e transformadora entre o IFPA e a sociedade. Tal processo apoia-se na valorização e troca de saberes para a solução de problemas, e no diálogo entre a função social dos Institutos e as políticas públicas, buscando a efetivação de direitos sociais e o exercício pleno da cidadania, articulada ao combate a discriminações, preconceitos e desigualdades em acordo com as políticas de ações afirmativas e de inclusão social.

Assim, a extensão é estratégia para a criação de redes de conhecimento, para a inclusão de atores sociais nas políticas institucionais, bem como para a própria inserção e o acompanhamento dos estudantes na comunidade de forma articulada com o mundo do trabalho (IFPA, 2014).

Fundamentado na Política Nacional de Extensão (FÓRUM..., 2012), as diretrizes gerais de extensão do Instituto Federal do Pará, visam ampliar as ações de educação em ciência, tecnologia e inovação no Estado, viabilizando a promoção do desenvolvimento social, científico e tecnológico local. As diretrizes são divididas então em 5 (cinco) vertentes:

a) Interdisciplinaridade: as ações de Extensão propiciam a realização de atividades acadêmicas de caráter interdisciplinar, a integração de áreas distintas do conhecimento e a possibilidade de 
construção de uma nova forma de fazer ciência.

b) Articulação entre as atividades de Extensão, Ensino e Pesquisa: o princípio da interdisciplinaridade caminha para a perspectiva da interlocução e integração das atividades de ensino, pesquisa e Extensão no fazer acadêmico. A relação entre o ensino e a extensão conduz a mudanças no processo pedagógico, numa relação em que alunos e professores se constituem em sujeitos do ato de aprender. Por outro lado, a extensão possibilita a democratização do saber científico e tecnológico, num movimento de mão dupla de difusão do que é produzido sistematicamente e a sua retomada por meio da ressignificação e reelaboração desenvolvida pelos atores sociais. Essa relação entre a pesquisa, o ensino, a produção de conhecimentos e a extensão é dinâmica e contribui para a transformação da sociedade num processo de incorporação de novos modos de vida e de uso de tecnologias, capazes de operacionalizar efetivamente a relação entre teoria e prática.

c) Relação dialógica entre o Instituto e a sociedade: a interação entre teoria e prática potencializa a articulação entre os saberes sistematizados, acadêmicos e populares. Essa interação abre canais para a produção de novos conhecimentos resultantes do encontro do Instituto com o cotidiano das comunidades e pela efetiva participação dos setores sociais no reconhecimento e na compreensão do desafio da produção acadêmica.

d) Relação social de impacto: as atividades de extensão conferem relevância às ações voltadas para os interesses e necessidades da maioria da população, aliada aos movimentos de superação de desigualdades e de exclusão social. Nesse contexto, busca-se articular programas capazes de focalizar o desenvolvimento regional e o fortalecimento de políticas públicas de amplo espectro. Dessa forma, as ações são realizadas em conjunto com a sociedade, rejeitando uma prática assistencialista em que as ações são ofertadas às pessoas, sem uma análise efetiva de suas demandas e necessidades. 
e) Impacto e transformação: estabelecimento de uma relação entre o Instituto e outros setores da sociedade, com vistas a uma atuação transformadora, voltada para os interesses e necessidades da maioria da população e implementadora de desenvolvimento regional e de políticas públicas. Essa diretriz consolida a orientação para cada ação da extensão frente à complexidade e a diversidade da realidade, sendo necessário eleger as questões mais prioritárias, com abrangência suficiente para uma atuação que colabore efetivamente para a mudança social.

Portanto, nesse artigo, discorreremos acerca da prática extensionista no Instituto Federal do Pará - IFPA, Campus Abaetetuba, e sua importância para o desenvolvimento da educação, ciência e tecnologia na Região do Baixo Tocantins Paraense.

Instituto Federal de Educação, Ciência e Tecnologia do Pará - IFPA, Campus Abaetetuba: do histórico à extensão

Abaetetuba é um município do Estado do Pará com uma extensão territorial, segundo o IBGE, de $1.610,75 \mathrm{~km}^{2}$. Localizado na região Norte do Brasil, esse município pertence à Mesorregião do

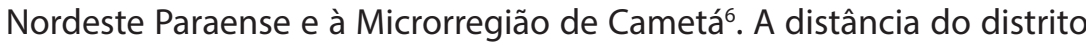
sede à capital do Estado é, em linha reta, de $60 \mathrm{~km}$ e de $110 \mathrm{~km}$ por via rodoviária (FERRANTI, 2013).

Quanto ao campus do Instituto Federal de Educação, Ciência e Tecnologia, no município de Abaetetuba, teve por origem, a partir da Unidade de Ensino Descentralizada (UNED), a qual recebeu autorização de funcionamento por meio da Portaria no 698/09/2008 com publicação em 10/06/2008. Ainda vinculado ao Centro Federal de Educação Tecnológica do Pará - CEFET-PA, a UNED de Abaetetuba iniciou suas atividades no dia 15 de outubro com a aula inaugural (BRASIL, 2008b).

6 A Microrregião de Cametá é composta pelos municípios de Abaetetuba, Baião, Cametá, Igarapé-Miri, Limoeiro do Ajuru, Mocajuba e Oeiras do Pará. 
O IFPA Campus Abaetetuba passou a ser assim denominado a partir da criação da Rede Federal de Educação Profissional, Científica e Tecnológica, que cria os Institutos Federais de Educação, Ciência e Tecnologia por meio da Lei 11.892, de 29 de dezembro de 2008 (BRASIL, 2008a).

Os primeiros cursos ofertados no ano de 2008 foram: Técnico em Edificações e Informática, integrados ao Ensino Médio; Técnico em Informática, Aquicultura, Pesca e Saneamento, subsequentes ao Ensino Médio, todos em regime regular de ensino.

No ano de 2009, foi implantado no Campus Abaetetuba o curso de Graduação em Licenciatura em Ciências Biológicas, Licenciatura em Educação no Campo e Especialização em Educação no Campo, estes últimos em regimes intervalares de ensino.

Em 2010, foi ofertado o Curso de Pós-graduação Latu Sensu PROEJA, em regime regular de ensino e o curso de Licenciatura em Pedagogia pelo PARFOR- Plataforma Freire.

Atualmente, no IFPA Campus Abaetetuba, funcionam os seguintes cursos: Licenciatura em Biologia, Técnico Subsequente ao Ensino Médio (Aquicultura, Edificações, Informática, Meio Ambiente, Pesca, Saneamento e Segurança do Trabalho) e Técnico Integrado ao Ensino Médio (Edificações, Informática, Mecânica e Meio Ambiente).

Além do mais, são ofertados cursos de Programas do Governo Federal como: Programa Mulheres Mil, Bolsa Formação Programa Nacional de Acesso ao Ensino Técnico e Emprego (PRONATEC), este com extensão nos pólos dos municípios de Moju, Acará e IgarapéMiri, além dos cursos de Licenciatura em: Pedagogia, Biologia, Física e Educação no Campo pelo PARFOR e os Cursos do E-TEC/Brasil.

Dentre os motivos que levaram à implantação do IFPA, no município de Abaetetuba, podemos destacar: a intenção do Governo Federal na expansão da oferta de vagas para o segmento da Educação Profissional; o grande interesse manifestado pela comunidade da região 
do Baixo Tocantins; a necessidade de formação de profissional que atendesse à demanda do setor produtivo da região, apoiando a economia e buscando, em conjunto o desenvolvimento socioeconômico, local e regional.

Ações de extensão no IFPA, Campus Abaetetuba: do instituto à comunidade

Pensar práticas extensionistas no âmbito dos Institutos Federais é entender a dinâmica entre o saber e o fazer no interior do campus e da comunidade. Já dizia o educador brasileiro, Paulo Freire "O conhecimento não se estende do que se julga sabedor até aqueles que se julga não saberem; o conhecimento se constitui nas relações homemmundo, relações de transformação, e se aperfeiçoa na problematização crítica destas relações". (FREIRE, 2006, p. 36).

Portanto, as práticas de extensão constituem um processo educativo, cultural e científico que articula o ensino e a pesquisa (e inovação) de forma indissociável, para viabilizar uma relação transformadora entre o IFPA - Campus Abaetetuba e a sociedade da Região do Baixo Tocantins Paraense.

A produção do conhecimento via extensão, se faz na troca de saberes sistematizados, acadêmicos e populares, tendo, como consequência, a democratização do conhecimento, a participação efetiva da comunidade na atuação do Instituto e uma produção resultante do confronto com a realidade.

De acordo com o Plano de Desenvolvimento Institucional (PDI), anos 2014-2018, as dimensões das ações e a base conceitual comum aos IFs, são resguardadas na política de extensão do IFPA (IFPA, 2014), a saber:

a) Projetos Tecnológicos: Atividades de pesquisa e/ ou desenvolvimento em parceria com instituições públicas ou privadas que tenham uma interface de aplicação. 
b) Serviços Tecnológicos: Consultoria, assessoria e prestação de serviços para o mundo produtivo e do trabalho.

c) Eventos: Ações de interesse técnico, social, científico, esportivo, artístico e cultural favorecendo a participação da comunidade externa ou interna.

d) Projetos Sociais: Projetos que agregam um conjunto de ações, técnicas e metodologias transformadoras, desenvolvidas ou aplicadas na interação com a população e apropriadas por ela, para inclusão social, geração de oportunidades e melhoria das condições de vida.

e) Estágio e Empregos: Compreende todas as atividades de prospecção de oportunidades de estágio/emprego e a operacionalização administrativa do estágio.

f) Cursos de Extensão: Ação pedagógica de caráter teórico e prático, com critérios de avaliação definidos e oferta não regular.

g) Projetos Culturais Artísticos e Esportivos: Compreende ações referentes a atividades culturais, artísticas e esportivas.

h) Visitas Técnicas e Gerenciais: Interação das áreas educacionais da instituição com o mundo do trabalho.

i) Empreendedorismo e Cooperativismo: Apoio à formação empreendedora com o subsídio de programas institucionais.

j) Acompanhamento de Egressos: Constitui-se no conjunto de ações implementadas que visam acompanhar o itinerário profissional do egresso, na perspectiva de identificar cenários junto ao mundo do trabalho e retroalimentar o processo de ensino, pesquisa e extensão.

k) Relações Internacionais: Tem por finalidade estabelecer intercâmbios e acordos de cooperação internacional, bem como celebração de convênios e parcerias, como um instrumento para a melhoria do ensino, da pesquisa e da extensão. 
Quanto à natureza da prática extensionista, as atividades de extensão do IFPA estão divididas entre as de caráter governamentais e as institucionais. As ações governamentais são aquelas que requerem pactuações e compromissos específicos, gerando formulações de Termos de Cooperação entre o IFPA, a Secretaria de Educação Profissional e Tecnológica - SETEC e agências de fomentos, visando a execução de programas vinculados às políticas públicas gerais de educação. As ações institucionais são aquelas estabelecidas na política institucional e são fomentadas com recursos específicos da matriz orçamentária institucional.

Assim, entre as ações desenvolvidas no IFPA - Campus Abaetetuba, cadastradas e executadas através de algumas dimensões acima elencadas, (e potencialmente aproveitadas pela comunidade) destacamos:

a) A caminho do Instituto: da informação à formação profissional (Responsável - Coordenação Geral de Extensão do IFPA Campus Abaetetuba): Ação que viabiliza à sociedade abaetetubense, a socialização da estrutura pedagógica e física do IFPA Campus Abaetetuba. Oportuniza-se a alunos do ensino fundamental das escolas públicas, os conhecimentos gerais e específicos sobre a estrutura e atuação do Instituto Federal no município, como opção para ingresso no mundo do trabalho, por meio da formação profissional técnica e tecnológica. $\mathrm{Na}$ oportunidade, divulga-se os cursos oferecidos (suas modalidades e áreas de atuação) e os programas oferecidos à comunidade.

b) Xadrez pedagógico: a ginástica da Inteligência (Coordenação - Professor João Chaves de Oliveira Neto): Este projeto apresenta os benefícios que o jogo do xadrez proporciona aos seus praticantes, avalia o desenvolvimento do raciocínio lógico, assim como sua contribuição na motivação e melhoria no aproveitamento tanto na vida acadêmica dos alunos do IFPA, Campus Abaetetuba, quanto na prática da cidadania. Portanto, esse projeto, materializa o jogo de xadrez, como ferramenta extremamente eficaz no processo de ensino aprendizagem, atuando na diminuição do índice de repetência, dependência, evasão e reprovação, 
permitindo ao praticante, o desenvolvimento de potencialidades primordiais para um bom desempenho escolar e social, por exemplo, concentração, raciocínio lógico matemático, memorização, rapidez de raciocínio, cálculo mental, respeito ao próximo, paciência, velocidade de raciocínio e etc. O caráter extensionista desse projeto é dado a partir da participação de alunos das escolas públicas atendidas no bairro do IFPA.

c) Avaliação do índice de aceitação do sistema de abastecimento de água do município de Abaetetuba (Coordenação - Professora Flávia Augusta Miranda Lisboa): A cidade de Abaetetuba, assim como a maioria dos municípios do interior do Pará, apresenta diversos problemas quanto ao saneamento básico, onde se pode detectar um sistema de abastecimento de água deficitário e insuficiente para atender a população da cidade, ocasionando diversos problemas de saúde pública, que podem ser diagnosticados nos relatórios da Secretaria Municipal de Saúde. Desta forma, esse projeto, avaliou o índice de aceitação do atual sistema de abastecimento de água do município de Abaetetuba, apresentando dados técnicos para a companhia detentora da concessão do sistema da cidade. O projeto foi desenvolvido a partir das seguintes etapas: apresentação dos alunos ao sistema de abastecimento de água; seleção dos bairros; elaboração dos questionários socioeconômicos em amostragem de 400 residências (100 em cada bairro); aplicação dos questionários; apresentação dos resultados obtidos à Direção do IFPA e Diretoria da empresa detentora da concessão do serviço de abastecimento de água do município, realização de oficinas sobre a importância da água nas escolas dos bairros.

d) Farmácia viva do IFPA (Coordenação - professora Alessandra Simone Santos de Oliveira Flor): A Amazônia brasileira apresenta um grande número de espécies vegetais corriqueira e largamente utilizadas com finalidades terapêuticas pela população, motivos pelos quais muitos estudos vêm sendo feitos no sentido de levantar tais conhecimentos. Entretanto, a maioria dos trabalhos etnobotânicos e etnofarmacêuticos realizados na região Amazônica ainda são poucos difundidos pela academia apesar dos incentivos e valorização do conhecimento tradicional de praticantes. Portanto, em parceria com 
o Hospital Nossa Senhora da Conceição, Diocese de Abaetetuba e Pastoral da criança municipal, o IFPA atua como parceiro externo, com a responsabilidade de elaborar, em conjunto, as ações metodológicas, assim como participar do desenvolvimento destas e da manipulação de remédios artesanais juntamente com a farmacêutica do Hospital, por fim, dando o total suporte à equipe do referido projeto.

e) Minicurso - Manutenção de Máquinas e Equipamentos (Coordenação - Professor Reuel Rocha dos Santos e Técnico Ângelo João Sousa da Silva): A dinâmica do avanço científico e tecnológico que vem ocorrendo nos dias atuais, as empresas brasileiras defrontam-se com o desfio de se reestruturar rapidamente, visando a competitividade. Considerando esse contexto, é necessário que o profissional esteja preparado, para atuar alinhado às exigências do mercado de trabalho. Nesse sentido, o minicurso de Manutenção de Máquinas e Equipamentos, atende à demanda local, com o objetivo de proporcionar a capacitação profissional em processos e técnicas de manutenção mecânica.

f) Curso Mecânica de Motos (Coordenação - Professor Reuel Rocha dos Santos e Técnico Ângelo João Sousa da Silva): Em Abaetetuba, é evidente que o meio de transporte mais utilizado é a motocicleta, e ao mesmo tempo, há uma carência de pessoal qualificado na área de mecânica de motos. Observa-se que poucos profissionais estão qualificados para o mercado de trabalho, assim, o curso de mecânica de motos, é destinado para a melhoria dessa mão de obra, e certificação daqueles que não possuem certificação a área. Esse curso foi oferecido tanto a alunos interessados, egressos, quanto à comunidade. Contou-se com o envolvimento de profissionais da área da Mecânica, Segurança do Trabalho e Sociologia.

g) Coleção Didática de Zoologia (Coordenação - Professor Pedro Chaves Baía Júnior): Entre os espaços pedagógicos e científicos do IFPA Campus Abaetetuba, temos o Laboratório e Coleção Didática Zoológica, como depositário de exemplares da vida animal da região do baixo Tocantins Paraense. Dentre as finalidades dessa coleção, encontramos: registro de espécies, instalação de acervo didático e local de referência 
para doação de espécimes de vertebrados e invertebrados. Esses fins priorizam melhorias para o ensino das aulas práticas e complementação para o aprendizado teórico de Zoologia e das disciplinas afins. Não apenas os cursos do IFPA fazem uso desse espaço, mas parte do ensino básico local, por meio de empréstimos de material para feiras de ciências e trabalhos escolares em geral.

h) Atleta Matemático Olímpico - AMO (Coordenação - Professor Edinaldo Fonseca Correa): O projeto tem como objetivo principal estimular o estudo da Matemática pelos alunos, desenvolvendo maior autonomia, raciocínio lógico-matemático e fazendo com isso que busquem uma formação mais completa para competirem e possibilitando um desenvolvimento educacional melhor, não só em matemática, como também nas outras áreas. Essa ação visa aprofundar os conhecimentos matemáticos dos alunos para competirem em olimpíadas nacionais e internacionais, em destaque, as Olimpíadas Brasileiras da Escola Pública - OBMEP promovido pelo Ministério da Educação-MEC. Ressalta-se o caráter extesionista desse projeto, que atende a alunos do ensino fundamental da Escola Estadual Leonardo Negrão de Sousa, localizada no mesmo bairro do IFPA Campus Abaetetuba.

i) Obra Legal - Processo de legalização de obra e o papel do Técnico em edificações (Coordenação - Professor Benedito Franciano Ferreira Rodrigues): O projeto leva à sociedade, as orientações necessárias para que, ao optar pela construção de um imóvel, o proprietário siga as determinações legais. Assim, garante a execução de uma obra de acordo com os parâmetros técnicos, evitando inconveniências como multas e/ ou gastos extras, além de contribuir para o bom desenvolvimento da sociedade. Desta forma, promove-se a valorização dos profissionais envolvidos nos processos da construção civil; combate-se a informalidade; estimula-se o respeito à legislação vigente, colaborando assim, para uma sociedade consciente, justa, bem estruturada e em constante desenvolvimento.

j) Avaliação do potencial nutricional da ração constituído pelo resíduo industrial do beneficiamento do palmito para a redução 
de custo dos avicultores da comunidade do Pirocaba, Abaetetuba-PA (Coordenação - Professor Roque Flor): A partir do desenvolvimento desse projeto, chegou-se ao entendimento que o custo de produção de aves está distante do ideal para os pequenos avicultores. O preço da alimentação está cada vez mais alto. Tendo em vista esse problema, buscou-se produzir uma ração alternativa mais barata, utilizando os resíduos produzidos pelas fábricas beneficiadoras de palmito na região, reduzindo o custo de produção, e na perspectiva de aumentar o lucro e diminuir as chances de possíveis fracassos na produção dos avicultores de pequeno porte. A produção da ração dos resíduos industriais do beneficiamento do palmito possibilita a redução de resíduos industriais para o meio ambiente, além de ser reaproveitado como alimentação alternativa para a avicultura na agricultura familiar e contribui para a economia dos avicultores da região, o qual é foco desse projeto que ocorre na comunidade rural Pirocaba, na Vila Nossa senhora de Nazaré.

k) Análise da qualidade da água através de indicadores microbiológicos (Coordenação - Professora Dirlene Ferreira da Silva): O tratamento da água potável, bem como a coleta, o tratamento e disposição adequada, o esgoto sanitário no meio ambiente são fatores fundamentais para a redução da transmissão de várias doenças, em todas as suas formas. Estes fatores evidenciam a importância do estudo da qualidade da água destinada ao consumo humano, por meio de análises de alguns parâmetros da água, a fim de que se obtenha o nível de qualidade do recurso hídrico. Assim, este projeto avalia a qualidade a água através de indicadores microbiológicos, devido a importância para a sociedade e para o meio ambiente, verificando a concentração dos indicadores microbiológicos, bactérias do grupo coliformes; analisando a qualidade a água consumida no município de Abaetetuba; investigando como ocorre a manipulação da água de consumo em alguns bairros.

I) Diversidade, uso e conservação da fauna silvestre no Baixo Tocantins (Coordenação - Professor Pedro Chaves Baía Júnior): Considerando que o IFPA Campus Abaetetuba, oferece o curso superior de Licenciatura em Biologia, contribuindo para a formação de professores de Biologia e Ciências, aplicada à realidade local, é relevante 
a prática de pesquisas sobre a diversidade e uso da fauna silvestre local, constituindo-se um importante instrumento de auxílio à formação dos discentes e na geração de novos conhecimentos à sociedade. Além do mais, estratégias de extensão envolvendo os discentes, voltadas à conscientização ambiental das comunidades locais e ao repasse de métodos de ensino e pesquisa sobre a fauna amazônica, contribuem com práticas mais duradouras de conservação e uso sustentável dos recursos naturais. Deste modo, este projeto viabiliza a avaliação da diversidade e do uso da fauna silvestre no Baixo Tocantins Paraense, identificando estratégias de conservação da biodiversidade local e contribui para a formação docente do curso citado acima.

m) Projeto LIFE - Laboratório Interdisciplinar de Formação de Educadores (Coordenação - Professor Josiel do Rego Vilhena): Esse projeto proporciona o desenvolvimento da práxis interdisciplinar com os professores e estudantes dos cursos de Licenciatura do IFPA, contribuindo assim, para a melhoria contínua desses cursos, tendo a contextualização e articulação dos saberes, bem como a interação com a sociedade, para motivar a inovação pedagógica nas práticas de ensino, na busca e construção coletiva de respostas ou mesmo, soluções para as problemáticas locais.

n) Hip Hop no IFPA (Coordenação - Professor Jairo da Silva e Silva): Na periferia, são desenvolvidas e praticadas diversas atividades culturais e discursivas, como as realizadas pela Cultura Hip Hop, composta pelos agentes b.boy/breaking com o break, do MC/rapper na produção e execução do rap, do grafiteiro com o graffiti e do DJ, na produção musical; ao concebermos esta cultura como potencialidade educacional, fundamentado na definição de interação social, evidenciase que há um silenciamento do discurso marginalizado da periferia na escola, mais especificamente o da Cultura Hip Hop. A escola como aparelho ideológico do estado, silencia as narrativas deste movimento, materializando o preconceito linguístico, discursivo e cultural, infelizmente, esse silêncio também vinha ocorrendo no campus do Instituto Federal do Pará, Campus Abaetetuba. Portanto, neste projeto, muito mais que a reflexão acerca de cultura periférica e seu silenciamento 
no ambiente escolar, a partir de oficinas dos elementos que compõe a Cultura Hip Hop, oportuniza-se a esta cultura como ferramenta de educação, conscientizando aos aprendizes, de seus direitos e deveres em busca do pleno exercício da cidadania. Essas oficinas têm como público alvo, tanto os alunos do Campus, quanto jovens e adolescentes que residem em bairros periféricos nesse município.

o) Cinemaeduca - Inserindo Cultura e Informação (Coordenação - Professor Douglas Oliveira e Oliveira): O projeto busca possibilitar à utilização da arte cinematográfica de forma interdisciplinar, através do incentivo a produção de filmes, longas e curtas-metragens, que serão escritos, criados, apresentados por nossos próprios alunos, a partir de temas preestabelecidos pelos professores. Tais temas também serão discutidos com a sociedade, principalmente nas escolas municipais e estaduais de Abaetetuba, a partir da exibição do material produzido pelos alunos do IFPA, na busca de expandir o conhecimento adquirido aos demais centros educacionais. Além disso, o projeto busca estimular a exibição de filmes nacionais como recurso didático para inserção de temas transversais na sala de aula, como forma de ampliar o espaço de lazer e enriquecimento cultural, incentivando a formação crítica, sociocultural e política no âmbito institucional.

p) Projeto Rádio Educativa (Coordenação-Professor Jairo da Silva e Silva): Pensado a partir da disciplina de Língua Portuguesa, é o núcleo de comunicação de rádio com finalidade pedagógica, apresentando as seguintes vantagens: melhorias no espaço de convivência dos alunos, aproximação e integração escola-aluno, ampliação das possibilidades de práticas inter e transdisciplinares, favorece o protagonismo juvenil, complementa o aprendizado, amplia a capacidade intelectual e as habilidades dos participantes, dá voz à comunidade escolar, cria condições para melhoria da comunicação institucional.

q) Plataformas virtuais (Coordenação - Professor Wander Wilson de Lima Cardoso): Esse projeto estuda as plataformas virtuais de aprendizagem de forma a selecionar algumas gratuitas, com padrão de qualidade de forma ser utilizado por alunos egressos do curso de 
informática, com os objetivos de facilitar suas entradas no mercado de trabalho e no nível superior, e ainda, proporcionar subsídios para que os que já estão na ativa, consigam melhores colocações.

r) Resignificando a Formação Continuada dos Professores da EJA na Rede Municipal de Ensino de Abaetetuba (Coordenação Maria Rosilene Maués Gomes): Esse projeto contribui com a formação continuada dos professores da rede pública municipal de Abaetetuba. Foi pensado a partir da participação dos alunos do curso de Biologia na disciplina Vivência da Prática Educativa com ênfase na educação de jovens e adultos, onde se verificou sérios problemas relacionados à qualidade dessa modalidade de ensino, sobretudo no que diz respeito às metodologias utilizadas em sala de aula. Desta forma, este projeto em parceria com a Secretaria Municipal de Ensino, inicialmente, atende a 50 professores (20 da zona urbana, 15 da zona rural e 15 da região das ilhas), contribuindo com a formação dos professores que atuam com uma parcela da sociedade a quem historicamente tem sido negado o direito a uma educação de qualidade.

Desta forma, ressaltamos que estas são algumas das ações desenvolvidas pelo Instituto Federal do Pará - Campus Abaetetuba, fortalecendo, assim, o tripé da educação: ensino, pesquisa (e inovação) e extensão, demarcando o seu lugar como instrumento promotor de desenvolvimento da Região do Baixo Tocantins Paraense.

Programas do Governo Federal em Abaetetuba:ações governamentais desenvolvidos pelo IFPA na Região do Baixo Tocantins Paraense

Além das ações acima relatadas, no IFPA - Campus Abaetetuba são ofertados cursos de Programas do Governo Federal, tais como: Bolsa Formação - Programa Nacional de Acesso ao Ensino Técnico e Emprego - PRONATEC (este com extensão nos pólos dos municípios de Moju, Acará e Igarapé-Miri), Programa Mulheres Mil, cursos do e-TEC/ Brasil, além dos cursos de Licenciatura em: Pedagogia, Biologia, Física e Educação no Campo pelo PARFOR. 
A Bolsa-Formação é uma ação no âmbito do PRONATEC - Programa Nacional de Acesso ao Ensino Técnico e Emprego, que diz respeito à oferta de vagas gratuitas em cursos técnicos e de formação inicial e continuada, ou de qualificação profissional. Seu público prioritário é constituído por estudantes da rede pública, trabalhadores, beneficiários dos programas federais de transferência de renda, estudantes que tenham cursado o ensino médio completo em escola da rede pública ou em instituições privadas na condição de bolsista integral, pessoas com deficiência, populações do campo, indígenas, quilombolas e afrodescendente, entre outros.

O PRONATEC é o Programa Nacional de Acesso ao Ensino Técnico e Emprego, foi criado pelo Governo Federal, em 2011, por meio da Lei 12.513/2011, com o objetivo de expandir, interiorizar e democratizar a oferta de cursos de educação profissional e tecnológica no país, além de contribuir para a melhoria da qualidade do ensino médio público (BRASIL, 2011b).

O Instituto passou a atuar no âmbito da Bolsa-Formação desde 2011, por meio da oferta de 7.380 vagas, sendo implementadas 6.035 através de 169 turmas, com 1.242 .600 horas-aulas ministradas ao longo de 2012 e 2013.

Até o final de 2013, o Instituto atuava em 75 municípios (Câmpus, polos e unidades remotas) com a oferta de 221 cursos, divididos em 253 turmas, totalizando 8.650 vagas através da Bolsa-Formação, que tem como objetivo expandir, interiorizar, democratizar e qualificar a oferta de cursos de educação profissional e tecnológica, levando em conta os arranjos produtivos, sociais, culturais, locais e regionais além das necessidades das populações envolvidas.

A partir de 2014 o IFPA passa atuar no PRONATEC com 18 (dezoito) câmpus, ampliando o seu campo de ofertas, tendo em vista a expansão da rede institucional, ampliando assim os municípios a serem beneficiados com os câmpus implantados. 
Em Abaetetuba, esse programa teve início em Outubro de 2013, atendendo a demanda de cerca de 500 alunos nos Cursos de Produtor de Mandioca, Agricultor Familiar, Auxiliar Técnico em Agropecuária, Instalador e Reparador de Redes de Computadores, Psicultor, Organizador de Eventos, Montador e Reparador de Computadores, Auxiliar de Fiscalização Ambiental, Agricultor Orgânico, Torneiro Mecânico e Mestre de Obras.

Além do PRONATEC, o IFPA - Campus Abaetetuba também oferta o Programa Nacional Mulheres Mil. Esse programa foi instituído pela Portaria do MEC no 1.015, de 21 de julho de 2011, que oportuniza a qualificação profissional e estimula o acréscimo da escolaridade visando à diminuição de problemas sociais em comunidades de baixo índice de desenvolvimento humano, bem como contribui com a ampliação da formação de profissionais para os mais diversos setores (BRASIL, 2011c).

O Programa Mulheres Mil vem de encontro à missão do Instituto Federal do Pará, que é promover uma educação inclusiva a uma parte da população, tradicionalmente, afastada da possibilidade do conhecimento técnico e inovador. Assim, a partir de 2011, o Programa Mulheres Mil passa a integrar o Plano Brasil Sem Miséria e sua oferta é estendida a todos os Estados Brasileiros através da SETEC/MEC. Com a meta de qualificar 100.000 (cem mil) mulheres até o fim de 2014, o governo brasileiro tem oportunizado por meio do Programa Mulheres Mil a formação profissional e incentivado o aumento da escolaridade de mulheres com idade de 16 a 70 anos, dentro dos Institutos Federais.

Nesse sentido, por está em consonância com a política inclusiva e com o desenvolvimento da região, o Instituto Federal de Ciência e Tecnologia do Pará - IFPA, desde 2011, promove a oferta do Programa Mulheres Mil. Essa oferta iniciou-se por quatro câmpus Abaetetuba, Altamira, Conceição do Araguaia e Breves.

Portanto, através desse Programa, o IFPA - Campus Abaetetuba contribui para a emancipação das mulheres em vários aspectos, por acreditar, que por meio da educação, realiza-se a 
promoção social e melhoria da qualidade de vida dos indivíduos, nessa perspectiva, oferece três cursos em geral, um no Eixo Tecnológico Produção Industrial: Costureiro Industrial do Vestuário, e dois cursos no Eixo Tecnológico Recursos Naturais: Avicultor e Horticultor Orgânico.

Outro Programa do Governo Federal que também é oferecido no IFPA - Campus Abaetetuba é o e-TEC/Brasil. A Rede e-Tec Brasil é uma ação do Ministério da Educação e tem como foco a oferta de cursos técnicos à distância, além de formação inicial e continuada de trabalhadores egressos do ensino médio ou da educação de jovens e adultos (BRASIL, 2011a).

A perspectiva da Rede e-Tec é a expansão e democratização da oferta de profissionalização voltada para o interior do país e também para as periferias das áreas metropolitanas orientando-se pelas necessidades de desenvolvimento econômico e social do estado. Para tanto, é tomada como referência as demandas dos trabalhadores por uma formação ampla e qualificada, as necessidades sociais e culturais e regionais identificados pelos estados. No Campus Abaetetuba é ofertado os cursos Multimeios Didáticos e nos pólo do município de Moju, Multimeios Didáticos e Alimentação Escolar.

O IFPA - Campus Abaetetuba, também participa do PARFOR. Trata-se do Plano Nacional de Formação de Professores da Educação Básica (BRASIL, 2009), que é resultado de um conjunto de ações do Ministério da Educação (MEC), em colaboração com as secretarias de educação dos estados e municípios e as instituições públicas de educação superior neles sediadas, para ministrar cursos superiores gratuitos e de qualidade a professores em exercício das escolas públicas sem formação adequada à Lei de Diretrizes e Bases da Educação Nacional - LDB, de dezembro de 1996 (BRASIL, 1996).

No caso do Campus de Abaetetuba, o IFPA oferece cursos de Licenciatura em: Pedagogia, Biologia, Física e Educação no Campo. 


\section{Considerações finais}

Muitas são as conquistas já alcançadas pelo IFPA - Campus Abaetetuba, em seus 08 anos de funcionamento, sobretudo no que diz respeito às ações de extensão, pois, demasiadas são as demandas de nossa comunidade. Portanto, a Extensão desse Campus, busca sempre atender a esses anseios, através de projetos e ações que materializam essa troca de saberes, e que consideram a realidade regional e local.

É certo que, apresentamos de maneira resumida as atividades extensionistas praticadas no/pelo IFPA - Campus Abaetetuba, pois, certamente, há muito mais ações executadas, que também tem colaborado para o desenvolvimento social, científico e tecnológico de nossa região.

Assim, a cada dia, através da Extensão (integrada ao Ensino, Pesquisa e Inovação), o Instituto Federal de Educação, Ciência e Tecnologia, no município de Abaetetuba, busca oferecer uma educação de qualidade, transformadora, democrática, pautada no diálogo e no respeito às particularidades regionais, principalmente, locais.

\section{Referências}

BAKHTIN, M. Marxismo e Filosofia da Linguagem. 7. ed. São Paulo: Hucitec, 1995.

BRASIL. Presidência da República. Lei Federal n9.394, de 20 de dezembro de 1996. Lei de Diretrizes e Bases da Educação Nacional. Diário Oficial da República Federativa do Brasil. Brasília, DF. 1996.

- Presidência da República. Lei Federal n 11.892, de 29 de dezembro de 2008. Lei de Criação da Rede Federal de Educação Profissional, Científica e Tecnológica. Diário Oficial da República Federativa do Brasil. Brasília, DF. 2008a.

. Ministério da Educação. Gabinete do Ministro. Portaria no 698, de 9 de junho de 2008. Dispõe sobre a autorização do Centro Federal de 
Educação Tecnológica do Pará - CEFET-PA a promover o funcionamento de sua UNED de Abaetetuba - PA. Diário Oficial da República Federativa do Brasil. Brasília, DF. 2008b.

- Ministério da Educação. Gabinete do Ministro. Portaria Normativa no 9, de 30 de junho de 2009. Institui o Plano Nacional de Formação dos Professores da Educação Básica no âmbito do Ministério da Educação. Diário Oficial da República Federativa do Brasil. Brasília, DF. 2009.

. Presidência da República. Decreto no 7.589, de 26 de outubro de 2011. Decreto que Institui a Rede e-Tec Brasil. Diário Oficial da República Federativa do Brasil. Brasília, DF. 2011a.

Presidência da República. Lei Federal n 12.513, de 26 de outubro de 2011. Lei de Instituição do Programa Nacional de Acesso ao Ensino Técnico e Emprego (PRONATEC). Diário Oficial da República Federativa do Brasil. Brasília, DF. 2011b.

. Ministério da Educação. Gabinete do Ministro. Portaria no 1.015, de 21 de julho de 2011. Dispõe sobre a Instituição do Programa Nacional Mulheres Mil. Diário Oficial da República Federativa do Brasil. Brasília, DF. 2011c.

FERRANTI, A. A Política educacional no Município de Abaetetuba (PA) no período de 2005-2008: Realidade e limites. 2013. Dissertação (Mestrado em Educação) - Instituto de Ciências da Educação, Universidade Federal do Pará, Belém. 2013.

FÓRUM de Pró-reitores de Extensão das Universidades Públicas Brasileiras. Indissociabilidade ensino-pesquisa-extensão. Brasília, DF: MEC, 2012. 100 p. (Coleção Extensão Universitária).

FREIRE, P. Pedagogia da Autonomia: saberes necessários à pratica educativa. 34. ed. São Paulo: Paz e Terra, 2006.

IFPA. Plano de Desenvolvimento Institucional 2014-2018. Disponível em: <http://www.ifpa.edu.br/documentos-institucionais/dcom/ pdi/1124-pdi-2014-2018-e-res-189-2014-consup/file>. Acesso em: 20 ago. 2016. 